Int. J. Electrochem. Sci., 14 (2019) $6108-6122$

\title{
The Relation between Structure and Corrosion Protection Performance of Hybrid Nanonanofibrous silica/Sol-Gel Film
}

\author{
Yadong Fan, Yongjie Cao, Junxi Zhang* \\ Shanghai Key Laboratory of Material Protection and Advanced Material in Electric Power, Shanghai \\ University of Electric Power, Shanghai, 200090, China \\ *E-mail: zhangjunxi@ shiep.edu.cn
}

doi: $10.20964 / 2019.07 .66$

Received: 6 March 2019 / Accepted: 1 May 2019 / Published: 10 June 2019

The purpose of this work is to study the effect of nanofibrous $\mathrm{SiO}_{2}$ on the corrosion protection performance of the sol-gel film coated on AA5052 aluminum alloy. The structure and surface morphology of the hybrid film ware evaluated by Transmission electron microscope (TEM) and Scanning electron microscopy (SEM), the result highlighted that the surface of composite films appears uniform and the nanofibrous $\mathrm{SiO}_{2}$ was evenly dispersed in the film. By analyzing the results of infrared spectroscopy, the addition of nanofibrous $\mathrm{SiO}_{2}$ enhanced the cross-linking of the sol-gel film. The electrochemical behavior of coated samples was determined by electrochemical test. The corrosion protection performance of the sol-gel film had a great improvement with addition of nanofibrous $\mathrm{SiO}_{2}$, the optimal additive concentration was $1 \mathrm{mg} / \mathrm{ml}$ at which the hybrid film showed the best corrosion protective performance in $3.5 \% \mathrm{NaCl}$ solution. From the result of potentiodynamic polarization, the corrosion rate of sample coated with the sol-gel film with $1 \mathrm{mg} / \mathrm{ml}$ nanofibrous $\mathrm{SiO}_{2}$ was about 6 times slower than pure sol-gel film coated sample.

Keywords: nanofibrous $\mathrm{SiO}_{2}$; TEOS film; corrosion protective properties; electrochemistry

\section{$\underline{\text { FULL TEXT }}$}

(C) 2019 The Authors. Published by ESG (www.electrochemsci.org). This article is an open access article distributed under the terms and conditions of the Creative Commons Attribution license (http://creativecommons.org/licenses/by/4.0/). 